\title{
Intraoperative Respiratory Injury
}

National Cancer Institute

\section{Source}

National Cancer Institute. Intraoperative Respiratory Injury. NCI Thesaurus. Code C78388.

Damage to the respiratory system during a surgical procedure. 